\title{
EL CONCEPTO DE TRASCENDENCIA Y LA CUESTION DEL ORIGEN DEL DERECHO: NOTAS PARA UNA APROXIMACION AL PROBLEMA
}

\author{
Raúl Madrid Ramírez \\ Departamento de Filosofía del Derecho \\ Pontificia Universidad Católica de Chile
}

\section{La cuestión de la trascendencia del Derecho}

Se discute si el derecho tiene su origen en sí mismo o en algo distinto de sí mismo. Por derecho, a la hora de analizar la proposición anterior, puede entenderse aquello que le es debido a cada uno, o bien la norma jurídica que, considerada en unión con otras, da origen al ordenamiento jurídico o sistema jurídico ${ }^{1}$. Esta última cuestión en los términos -ordenamiento o sistema- depende de la perspectiva epistemológica que se adopte, y no empece directamente a nuestro tema.

Es preciso tener en cuenta que la distinción antes mencionada entre el derecho como la cosa debida y el derecho como norma carece de sentido si se estima que absolutamente todo lo debido proviene de la norma. Como se da el caso de que la discusión entre iusnaturalismo y positivismo no afecta, entre las dos posibilidades antes indicadas, a la teoría de la norma (es decir, ninguna de las dos tesis niega que el derecho esté constituido por normas jurídicas), entenderemos en lo sucesivo y para los efectos de estas notas, derecho en el sentido de norma jurídica. En efecto, para quienes sustentan la tesis de la existencia de un Derecho Natural que actúe como fundamento del derecho escrito (opinión que nosotros compartimos), basta con probar que la ley de un ordenamiento jurídico no se autofundamenta, para demostrar oblicuamente que el derecho de cada individuo tiene otras causas distintas de la norma jurídica; y para aquéllos que nieguen toda relación entre los conceptos de norma y naturaleza, basta con demostrar que la ley es autosuficiente en lo relativo de la creación de los derechos individuales, para que carezca de sentido la discusión sobre supuestas causas de éste, distintas de la norma.

A la hora de preguntarse por el origen de una norma jurídica- es decir, del derecho-, es plausible considerar las siguientes posibilidades:

1 No parece necesario hacer aquí una distinción entre derecho y ciencia del derecho como nos recuerda Calsamiglia, pues desde el punto de vista del origen, la confusión no se plantea. Vid Calsamiglia, A., Introducción a la ciencia jurídica; Barcelona, Ariel, 1986, p.49 
- La norma se genera a sí misma

-La norma se genera por otro, al que denominamos legislador.

Dentro de esta segunda posibilidad, caben a su vez dos alternativas: La norma es indistinguible de la voluntad que la genera; o bien no lo es en cuanto que la voluntad ha de plegarse a un cierto contenido preexistente en la norma, que puede ser también, en principio, una voluntad ${ }^{2}$, aunque nosotros sostendremos con Tomás de Aquino que se trata primariamente de una razón ${ }^{3}$.

Que la norma se autogenera es, desde luego, una tesis imposible, y sólo cuenta como posibilidad lógica, del mismo modo que no puede sostenerse que algo sea causa de sí mismo sin caer en una contradicción igualmente lógica, cuyo fundamento es desde luego metafísico ${ }^{4}$.

No cabe tampoco interpretar la tesis iusnaturalista en este sentido, pues si bien es cierto que en dicha doctrina la ley aparece como una entidad independiente y superior al acto particular de un legislador humano, ello no significa que dicha norma se autocause con independencia de todo legislador ${ }^{5}$. Además, la acción del legislador humano es en realidad mucho más activa, dentro de la teoría clásica del Derecho Natural, de lo que suponen algunas interpretaciones contemporáneas que parten del iusnaturalismo racionalista ${ }^{6}$.

Si la norma no opera como causa de sí misma, necesariamente proviene de un legislador, que constituye su origen. Se abren allí las dos posibilidades antes mencionadas: puede ser que la ley dependa por completo de la subjetividad de quienes la dictan - o de quienes han de ser gobernados por ella-, o puede ser que la subjetividad del legislador y de los súbditos deba adecuarse a otra cosa distinta y anterior a sí misma. Esta problemática abarca tanto el campo del contenido de la norma jurídica, como el de la procedencia de su fuerza imperativa ${ }^{7}$. Es decir, en el plano del contenido: si una determinada

Sobre la reducción de lo normativo a la voluntad del legislador, vid,el fundamento propuesto por Ockham, In Sententiarum, q. 14 ss.

3 Sum Teol., I-II, q.93 a.1

$4 \quad$ Sum.Teol., I, q.3 a.7

5 Sum. Teol., I-Il, q.91 a.1. Todo el conjunto del universo se halla sometido al gobierno de la razón divina. Dios es, en este sentido, el primer legislador; el analogado superior en virtud del cual todo otro legislador se predica tal. Cf.también Victoria, Relación de aquello a que está obligado el hom bre cuanto alcanza el uso de razón,ll,n.9

6 La crítica de Peces-Barba, por ejemplo, en el sentido que del iusnaturalismo se concluiría la existencia de dos derechos vigentes en una sociedad -el natural y el positivo- no puede sostenerse frente a la posición clásica. Esto, a nuestro juicio, por dos motivos: primero, porque el natural es fundamento del positivo, pero no todo derecho natural es positivo; y segundo, porque una vez positivado, ese derecho es también natural, para ese sistema jurídico concreto, en el tiempo y el espacio.

7 Además de la distinción clásica contenido/Mandato en la ley, Vid. también el fundamental tratamiento de von Wright sobre el particular. El lógico finlandés sitúa el "contenido" dentro de lo que él denomina el "núcleo normativo", y lo presenta como uno de los componentes de una norma prescriptiva. El "mandato" se halla implícito, por el contrario, en la propia estructura pres- 
conducta es jurídicamente válida por haberla considerado de esta forma el legislador concreto o la conciencia colectiva de los súbditos, o lo es porque la opinión del legislador particular y de los gobernados se ajusta a un cierto modo de ser que se halla constituido previamente a la voluntad; $y$, en el plano del mandato: si la fuerza imperativa de la norma positiva emana de su formalización y positivación en un ordenamiento jurídico específico, o, por el contrario, se remonta a la imperatividad de alguna otra ley no positiva que es anterior a la norma escrita.

Es aquí donde queremos fijar la cuestión de la trascendencia ${ }^{8}$. El derecho será una realidad inmanente si la norma y la voluntad que la crea se identifican; por el contrario, le llamaremos trascenderite si dicha unidad es puramente accidental (un legislador humano, en un espacio y tiempo determinados, se pliega a la normatividad preexistente, y con ello la especifica en un derecho positivo) .

Cada una de estas tesis se origina en modelos epistemológicos abstractos, que pueden ser considerados desde la perspectiva de una realidad trascendente, tanto en lo que se refiere al núcleo de sus planteamientos, como en las consecuencias jurídicas que de dichas reflexiones especulativas se derivan.

Antes de emprender el análisis de estos dos modelos desde el punto de vista del concepto de trascendencia, nos parece que conviene hacer una breve inflexión etimológica sobre la palabra que nos ocupa, así como sobre la noción misma que ésta supone.

El término español "trascendencia" se origina en la voz latina transcendo, compuesta del prefijo trans, cuyo significado indica "mas allá" (análogo a supra), y la palabra scando, que traducimos por "escalar", o "subir"9.

criptiva de la regla, sin el cual, no se trataría de un uso prescriptivo del lenguaje. Cf. Norm and Action. A logical Inquiry, Routledge and Kegan Paul, Londres, 1963, p, 71 ss

8 Desde luego, hay otros sentidos de la voz. Consideremos los dos que siguen: - Puede hablarse de acción inmanente o acción trascendente. Como es sabido, Aristóteles distingue dos tipos de acciones: actio transiens y actio manens. primer tipo comprende un movimiento transitivo, que se recibe en un sujeto distinto de aquel en el cual se produce. En este tipo de acciones se distingue claramente el acto mismo de su resultado: no es lo mismo, por ejemplo, "atar" que "haber atado". La segunda modalidad, en cambio, es lo contrario se trata de un acto cuyo resultado es recibido por el propio sujeto que lo produce. No hay aquí diferencia entre el acto y el resultado, es una acción intransitiva. Desde el punto de vista de la transitividad de la acción, el acto inmanente es más completo y perfecto que el trascendente, pues no requiere salir de sí mismo para desarrollarse en su naturaleza específica. La actividad superior del hombre, el pensamiento especulativo, es inmanente; lo mismo que el acto puro en la línea del ser. Es trascendente, además, la existencia del objeto como tal frente al sujeto. Este debe salir de si mismo hacia aquella cualidad capaz de poner en movimiento la potencia de la razón. Poner el énfasis en el objeto o en el sujeto a la hora de describir el proceso cognoscitivo hace variar el modelo especulativo de que se trate. La discusión sobre este tipo de trascendencia está en la base del debate central que exponemos aquí, pero no es la misma cuestión, tal como se verá más adelante.

n El Oxford Classical Latin Dictionary considera como origen del verbo latino transcendo el del verbo scando, cuyos significados sistematiza así:Trepar hasta el tope, ascender, escalar; mover o ser movido (una cosa); trepar (respecto de plantas); extender o inclinarse (una colina, un edificio), declinar hacia; avanzar en años hacia un punto; escandir (un verso).

Ahora bien, el idioma clásico usa el verbo que nos interesa con las siguientes acepciones: trepar, pasar, ir más allá; cruzar (un río, etc.); ir sobre o a través de (un lugar); sobrepasar, transgredir 
El sentido más inmediato del término latino -y en consecuencia, del español-, apunta como puede verse a una referencia espacial; una metáfora de lugar. La realidad que traspasa ese límite es, en tales términos, una "realidad trascendente"; mientras que la acción o efecto de ubicarse más allá del respectivo límite, adquiere el nombre de "trascendencia". En esta perspectiva etimológica primitiva, "trascender" viene a ser idéntico a "pasar de un sitio o ámbito a otro", sin hacer referencia todavía al hecho de si dicho paso indica o no una evolución respecto del lugar anterior; aún cuando podría argumentarse que la noción de "escalamiento" antes mencionada apunta de alguna manera a un cambio de estado en el orden de lo bueno y de lo malo, por cuanto lo que se encuentra "más arriba" se presume "mejor" que aquello ubicado "más abajo"; sin embargo, tal cosa no pasa de apoyarse en un supuesto ajeno a la estricta relación lógica de los términos lingüísticos implícitos en la palabra que analizamos.

Este contenido de superioridad o de superación al que hacemos referencia es agregado realmente por la tradición posterior al uso del término en el sentido descrito de la cual surge la palabra tal como ha llegado hasta nuestros días-. Esta consideración formal insertará la voz en contextos muy determinados, dentro de los cuales dejará de indicar el paso material de un espacio a otro, y adquirirá el significado con el que, en nuestros días, ha vuelto al lenguaje vulgar: superar un determinado estadio o límite (cualquiera; dependerá del contenido concreto), para pasar a otro de naturaleza más elevada.

Así como toda idea del mundo es realmente inútil si desconoce la evidencia sensible y no puede explicar la realidad de las cosas (de modo que toda concepción de lo real no puede sino medirse con la experiencia que ofrecen los sentidos), así también todo concepto -por muchos significados y casos del lenguaje que abarque- acaba extrayendo su sentido fundamental de aquel que lo pone en relación con el aspecto más íntimo de la realidad que constituye su referencia. Este significado primario será siempre aquél que, consecuente con el descubrimiento de los seres en su existencia, desborde inmediatamente después en la consideración de su esencia. Sin posición metafísica, no hay géneros de ningún tipo, ni existe lenguaje alguno que los exprese.

Consecuente con lo anterior, la noción más relevante que guarda la voz "trascendencia" parece ser propia del ámbito metafísico; y desde allí habrá de revertir en el terreno de la razón práctica, particularmente en el Derecho, objeto de nuestra actual investigación.

Suscribimos la afirmación de Schelsky en el sentido de que el concepto de "trascendencia" se logra, en su dimensión filosófica, a partir de la experiencia de que el hombre se encuentra en "búsqueda de realidad"10. La actitud especulativa consiste en la

(normas, pautas), exceder; pasar por sobre, omitir (detalles, etc.), hacer una transición en un argumento o narración.

En lo que se refiere al lenguaje medieval, el Lexicon Latinitatis Medii Aevi de Blaise (Brepols, 1975) menciona trascendes (como sinónimo de trascendentalis), trascendentia (como sustantivo), y el verbo transcendo, del que ofrece los siguientes significados: ser trascendente respecto de: $t$. materiam. Tomás de Aquino lq118, 2.; trascendentia, aliquam res: ser común a todas; $y$ quae omnen transcendunt imaginationem. 
tensión del sujeto respecto del mundo; ir más allá de las fronteras del propio yo, y relacionarse con aquello que se encuentra alrededor de tal manera que dicha relación constituya a la vez conocimiento y afirmación. Esta tensión se verifica en todos los individuos de la especie, en cuanto actúan "por naturaleza" a este respecto ${ }^{11}$. Ahora bien, una vez situados en el plano ontológico, verificamos el segundo momento especulativo del problema propuesto: aquello que trasciende nuestra subjetividad, ¿dónde o en qué se funda? El camino que siga la respuesta a esta interrogante constituye la historia de la filosofía occidental; hasta el punto de que podría llegar a afirmarse que las distintas opiniones filosóficas constituyen y precisan su núcleo más íntimo por la respectiva noción de trascendencia que utilizan y desarrollan ${ }^{12}$.

Planteada así la trascendencia, con sus dos momentos, o dos consecutivas problematizaciones teóricas, podemos comprobar que posee al menos las siguientes notas propias: referencialidad inmanente y naturaleza dialéctica. Explicaremos brevemente de qué se trata cada una de ellas.

La primera de estas características puede enunciarse así: la determinación o afirmación de una realidad cualquiera como trascendente significa al mismo tiempo la reducción de otra a la condición de inmanencia; mientras que la determinación o afirmación de una realidad como inmanente significa de inmediato trascenderla. Trascendencia es, por lo tanto, la culminación de un proceso constituido por una referencia retrospectiva. Todo concepto o término que exprese trascendencia o inmanencia es, constitutivamente y en su esencia, un concepto o un término relativo.

La naturaleza dialéctica fluye como consecuencia de esto: es trascendente lo que se encuentra en tensión respecto de lo inmanente; hasta el punto que no pueda la trascendencia predicarse de nada si no se predica correlativamente de algo la inmanencia. La formalidad dialéctica proviene justamente de la nota ontológica $y$, a la vez relacional, que hemos enunciado.

La visión metafísica tocante a los conceptos de "inmanencia" y "trascendencia" que hemos descrito, posee dos contenidos teóricos distintos y fundamentales; dos modelos particulares que se basan, como ya es posible comprender, en las dos grandes concepciones metafísicas que ha conocido el pensamiento de Occidente: por una parte, la afirmación de que el ser es con independencia del sujeto, y se puede conocer en un movimiento de éste hacia aquél; por la otra, la proposición de que el ser depende ontológicamente del sujeto, no sólo en su aprehensión, sino también en su existencia.

A estas dos visiones de la trascendencia vamos a referirnos seguidamente, para desarrollar, desde sus fundamentos especulativos, el alcance que la noción puede abrigar para la filosofía práctica y para el Derecho.

12 "La concepción del problema de la insuficiencia de la realidad como problema de la trascendencia está fundada en la tradición del pensamiento filosófico europeo" Simons, E., en Conceptos Fundamentales de Filosofía, Editorial Herder, Barcelona, 1979, Voz Trascendencia. 


\section{La trascendencia en el modelo metafísico}

La primera gran perspectiva de pensamiento metafísico que vamos a reseñar se inicia propiamente con Aristóteles ${ }^{13}$, y llega a su punto más alto con el Corpus Thomisticum.

El centro de esta reflexión es la existencia de un ser absolutamente trascendente al mundo sensible -el cual es llamado "Dios", "Lo Uno", "Primer Principio" (Ipsum Esse Subsistens), etc-, de cuya eficiencia éste procede; y dicha procedencia se verifica de un modo tan radicalmente constitutivo, que toda entidad es y existe por participación del ser propio de la entidad trascendente, y por lo tanto, mantienen su existencia que los conoce. Esta trascendencia absoluta de un ser ajeno al mundo, que en principio se puede entender como "total", se matiza sin embargo con el hecho de que uno de los términos de la relación no es una entidad necesaria ${ }^{14}$. Efectivamente, la existencia individual de cada ser concreto depende actualmente de la existencia perfecta del Ser Trascendente es lo que establece la calidad referencial y comunicativa del concepto en cuestión.

Dos son por lo tanto los conceptos claves de esta idea de trascendencia: por una parte, la noción de infinitud; por la otra, la de participación (que supone el concepto de analogía).

La infinitud no es el constitutivo formal del Ipsum Esse Subsistens; más bien constituye un punto de apoyo para decir lo que éste no es ${ }^{15}$. Desde la perspectiva gnoseológica, la noción de infinito supone la de lo finito; pues lo finito es materia de experiencia sensible, y todo conocimiento comienza por los sentidos. Se predica "finitud" de aquello que tiene límites, o que sólo alcanza a superar determinados límites en el orden formal del que se trate; mientras que llamamos "infinito" a una determinada realidad que supera todo límite posible, y se abarca o encierra -consecuencialmente- a sí mismo. Dicho de otro modo: finitud es propiedad de lo inmanente, por cuanto todo se constituye en inmanencia frente a aquello que trasciende y supera todo límite posible. Ahora

Es preciso entender bien esta afirmación. Los antecedentes de la filosofía aristotélico-tomista contienen muchos elementos que luego son desarrollados por ésta. El caso más claro es, probablemente, el de Parménides. Ya Heidegger ha destacado suficientemente que la estricta consideración del ser parmenídeo no puede sino llevar a la consideración del Ser en su diferencia; como distinto del ente y del género. Estas características se repetirían, según el filósofo alemán, en el esse tomista.

14 Los dos términos de esta relación de trascendencia que propone el pensamiento tradicional son, como es evidente, Dios y el universo. El mundo creado, aunque depende en su ser del Principio Trascendente, y se constituye en vértice de inmanencia respecto de la Causa Eficiente, es simple y meramente contingente para la trascendencia divina. Dicho de otro modo: aunque Dios es, en esta concepción, trascendente al universo creado, no deriva su trascendencia de la referencia al otro; sino que lo es per se y con independencia de toda otra entidad. Tal característica constituye la particularidad más propia de la relación Primer Principio-universo creado.

15 . El concepto de "infinito" es, sin embargo, una noción positiva, puesto que si lo finito expresa una determinada limitación, la negación de esa limitación conforma una afirmación. Scoto afirmó que el constitutivo formal de Dios era su propia infinitud, que estaba a su vez en la raíz de todas las otras perfecciones divinas. En Tomás de Aquino, en cambio, la infinitud proviene del propio ser subsistente de Dios, de tal manera que es infinito porque es su mismo ser, y no de manera inversa. Cf. Scoto, D., Opus'Oxoniense, I, d. 3, pars $1^{\circ}, q .2$ 
bien, el ser trascendente, al no aceptar en su esencia nada de potencialidad, no contiene tampoco limitación alguna, y es por lo tanto infinita, se encuentra más allá de todo otro existente $^{16}$. Así, es plenamente trascendente lo que es infinito; y la infinitud es consecuencia de la identidad de Dios en el seno de sí mismo, en el que no hay rastro alguno de potencia.

El segundo concepto relevante es el de "participación", por el motivo que sigue: la infinitud describe el Acto Puro cuya realidad es extramundana. A partir de la constatación de la existencia del universo, que realizan nuestros sentidos, la pregunta consecuente puede formularse así: ¿Es el Acto Puro e infinito una entidad ajena por completo al mundo sensible?. La respuesta, evidentemente, es negativa. Sabemos que el universo proviene directamente de la potencia activa de $\operatorname{Dios}^{17}$, por la cual lo crea ex nihilo ${ }^{18}$. El mundo depende de su. Causa Primera no sólo en cuanto creado, sino que esa misma creación inicial los conserva actualmente en el $\operatorname{ser}^{19}$, de tal modo que si la causa dejara de existir, simultáneamente lo harían sus efectos. Los distintos seres del mundo tienen parte en el ser gracias a aquél cuyo modo de ser constituye a la vez su propio existir. En este sentido, se dice que participan de él, puesto que participar es, precisamente, tener parte en el ser. Ahora bien, en la medida en que cada participante es un ser completo e individual, este sentido de participación no significa "ser una parte de la causa". El ser participado es un ser finito no al modo de una parte del ser, sino como algo que "tiene parte", pero es concreto y completo. precisamente por esta característica, el ser es análogo, aunque permanezca unívoco en su razón formal y metafísica ${ }^{20}$. Dicha condición analógica proviene de que es imposible separar en él lo diverso de lo uno (luego, no es unívoco); Pero tampoco puede separarse en él lo uno de lo diverso (no siendo por tanto una noción equívoca).

El sentido principal de la trascendencia escolástica es éste: La causa del mundo es extramundana, pero los seres del universo participan de dicha causa de un modo tal por el cual no se le identifican, pero tampoco pierden del todo la semejanza.

Desde este punto de vista, la voz "trascendental" designa las propiedades universales del ser -de aquello que constituye la participación - Esta noción halla, a su vez fundamento en Aristóteles, cuando afirma en el libro IV de la Metafísica - ya antes citadalo siguiente:

"Asi como hay también afecciones propias del Número en cuanto número, por ejemplo, la imparidad y la paridad, la conmensurabilidad y la igualdad, el exceso y el defecto, y éstas se dan en los números en sí y en sus relaciones mutuas (e igualmente lo sólido, lo inmóvil y lo movido, lo ingrávido y lo pesante tienen otras afec-

16 Cfr. Sum. Teol., I, q.7,a.1. También De Potencia, q1, a.2 Esta tesis supone la doctrina admitida hasta Suárez que el acto no se limita a sí mismo, sino que sólo se encuentra limitado por la capacidad receptiva de la potencia.

17 Suma Contra Gentiles,vol.I cap. XVI. Utilizo la traducción de M. Bergadá, Club de Lectores, Buenos Aires, 1951

Sum. Teol., I,q.XLV,a.1.

19 Sum. Teol., I, q. CIV,a.1 ad 4

20 Marc, A., Dialéctica de la afirmación, vol.l, Gredos, Madrid, 1964, p. 
ciones propias), así también el Ente en cuanto ente tiene ciertas afecciones propias, y éstas son aquellas acerca de las cuales es propio del filósofo investigar la verdad" ${ }^{21}$.

Ahora bien, estos determinados atributos o afecciones del Ente que ya menciona el Estagirita no son ni categorías (o también llamadas "denominación"22; "predicación". "predicamento" y "atributo" ${ }^{23}$ ) ni géneros. Preguntarse por su peculiaridad, explicita más la noción de trascendencia que intentamos desarrollar.

Un trascendental no es una categoría porque desde el punto de vista lógico, los atributos categoriales se consideran en cuanto no afirman ni niegan nada por sí mismas; sino solamente en la medida en que se encuentran ligadas a otras expresiones; el ser, por el contrario, está presente en toda entidad. Desde la perspectiva ontológica y éste es un segundo motivo-, las categorías constituyen los modos fundamentales de ser a los que se reduce toda realidad concreta. En este sentido, son "géneros supremos" del ente, en tanto descripción de modos reales de $\operatorname{ser}^{24}$.

Las propiedades del Ente no son tampoco géneros, porque su naturaleza supera la estricta consideración formalmente lógica de aquello que tiene mayor extensión, y por consiguiente, menor comprensión que otra forma de ser, a la que denominamos - por oposición - "especie". El ente no es un concepto, ni sus propiedades atributos lógicos. Y, consecuencialmente, al no ser el Ente un género, no puede-como sabemos-formar parte de ninguna definición, por cuanto "definir" es incluir algo dentro de un género y otorgarle una diferencia específica a partir de allí.

El mismo Aristóteles se ocupa de distinguir el conjunto de estas características propias del ente, de los géneros. El texto fundamental, aunque no único ${ }^{25}$, en que se verifica tal distinción, es el siguiente:

"Así pues, los principios de los entes serán tantos cuantos sean los géneros primeros; de suerte que el Ente y el Uno serán principios y substancias, pues estos son los que más se dicen de los entes. Pero no es posible que sean un género de los entes ni el Uno ni el Ente....... Pero si el Ente y el Uno no son géneros, tampoco serán principios, si es que los géneros son principios " 26

"En otros términos - dice Ferrater Mora, hablando de los trascendentales ${ }^{27}$, cualesquiera propiedades del Ente en cuanto ente no podrán ser géneros supremos del ente,

21 Met, D.2, 10046 10-18

22 Top., 107 a $3-18$

23 Top., 141a 4; Libro VII, cap. 1, 1028a 28; Analit. Prim ., cap. 1, 41 b 31 ss

24 No es éste, por supuesto, el concepto kantiano de predicamento; para quien deben ser entendidos como conceptos puros del entendimiento, y no de la realidad, en cuanto referidos a priori a los objetos de la intuición en general. Cf. KrV. Analítica Trascendental, Libro l, cap. 1

Cf. también por ejemplo: Met., L, 1, 1059 b 30 y Top., Libro VI, cap. 6, 144a 31b 11e

Met, G. 3, 998b 19-28. Una buena formalización de los argumentos que formula el Estagirita en contra de la identidad de las propiedades del Ente con los géneros y categorías, puede encontrarse en Bochensky, I.M., Ancient Formal Logic, pág. 34 
sino que serán modos diversos de decirse el ente (los trascendentales), todos los cuales serán convertibles (entre sí)".

Ahora bien, si para Aristóteles lo trascendental se enfocaba desde la perspectiva de que el objeto de la ciencia que estudia el ente en cuanto ente no es un género, su solución no supera el ámbito formal, puesto que la última actualidad que se desprende de sus concepciones es aquella propia de la forma, no de la existencia ${ }^{28}$.

El tratamiento más completo del concepto "trascendentales", como acepción metafísica fundamental de la palabra que nos interesa, corresponde en consecuencia a Tomás de Aquino; aunque el primer desarrollo específico del tema se halla realmente en la Summa de Bono, de 1256, cuyo autor es Felipe el Canciller. Nos referiremos brevemente a la cuestión según se encuentra en la obra del Aquinate ${ }^{29}$.

Santo Tomás no utiliza el término trascendentalis. Su incorporación al lenguaje escolástico parece deberse al franciscano Meyronnea; autor posterior a las enseñanzas del santo. La proposición principal del Aquinate sobre el tema que nos ocupa se encuentra en De Veritate ${ }^{30}$, y constituye el cuerpo de la respuesta a la cuestión "parece que lo verdadero es lo mismo que el Ente":

"Pues bien, aquello que primariamente concibe el entendimiento como lo más evidente y en lo cual vienen a resolverse todas sus concepciones es el ente, como dice Avicena al comienzo de su Metafísica ${ }^{31}$. Por eso es necesario que todas las otras concepciones del entendimiento se constituyan añadiendo algo al ente. Pero al ente no se le puede añadir nada que sea de una naturaleza extraña a él.... porque cualquier naturaleza es ente esencialmente. $Y$ en esto se apoya Aristóteles para probar en su Metafísica que el ente no puede ser género, sino que se dice que algo se añade al ente en cuanto expresa algún modo de él que no viene expresado por el nombre mismo de ente ${ }^{32}$.

El ente en tanto ente es, en consecuencia, lo primero que aprehende nuestro entendimiento, y no substancias particulares que participan de él. No es posible agregarle o quitarle nada que sea distinto de él. Sin embargo, esta realidad tan particular, a la que

\section{"Trascendental"}

28 8Cf. Met., H, I, 1028b ss. '¿Qué es el ente?' equivale a '¿qué es la substancia?' Gilson, por su parte, lo explica de la siguiente forma: "La existencia (en Aristóteles) es un mero prerrequisito del ser, no juega ningún papel en su estructura. El verdadero nombre aristotélico del ser es la substancia, la cual es idéntica a lo que un ser es.....la forma, pues, es el acto mismo por el cual una substancia es lo que es $y$, si un ser es primariamente o, como Aristóteles mismo dice, casi exclusivamente lo que es, cada ser es primariamente y casi exclusivamente su forma" Gilson, E., El Ser y los Filósofos, EUNSA, Pamplona, 1985, págs. 85-86

29 Hay muchas otras formulaciones de la teoría de los trascendentales, dentro de la misma escolástica. Nosotros centraremos nuestro análisis en la concepción tomista, por ser ésta la más solida en sus argumentos, y la que mayor influencia ha tenido hasta la modernidad filosófica.

I,1 ss

31 Metaphisica, Tract. I, cap. 6

32 De Veritate, q1, a.I Utilizamos la traducción de Jesús García López en la Doctrina de Santo Tomás sobre la Verdad, EUNSA, Pamplona, 1967 
nada puede agregarse, puede hacerse explícita a través de la formulación de aquello que conviene a todo ente o substancia, en la medida en que es ente: esto es, sus propiedades - atributos. Tales propiedades, llamadas "trascendentales del ser", o simplemente "trascendentales", son las siguientes: ens, res, unum, aliquid, verum, bonum, pulchrum $^{33}$.

El motivo por el que adquieren ese nombre, puede rastrearse en la intención de contraponer y distinguir el tipo de universalidad propio que les es característico, de aquella simplemente genérica; por muy máximo que éste sea ${ }^{34}$. Con ello, por lo tanto, retomamos ahora, desde una perspectiva más clara en orden a la discusión que nos interesa, el problema que se había esbozado un poco más arriba, en torno al carácter no genérico del ser $y$, en consecuencia, de sus atributos.

En este sentido, el fundamento de la trascendencia metafísica, tal como se usa por el planteamiento escolástico, viene a ser precisamente la necesidad de sobrepasar el límite de lo meramente individual, de modo que entre todas las cosas sensibles pueda existir algún vínculo que supere el enclaustramiento predicamental de la realidad. Se trata de la superación de un antiguo problema, que se inicia con Tales de Mileto y, a nuestro juicio, constituye la primera pregunta filosófica del hombre: la cuestión de la unidad de lo real. La solución griega fue -como sabemos- una respuesta esencial, desde los jonios hasta el propio Aristóteles. La diferencia radica, como dice González Alvarez, en que "los escolásticos llamaban trascendental al concepto que se extiende a todas las cosas, y por tanto, puede predicarse de ellas" ${ }^{35}$.

Con matices, Heidegger retoma esta línea de pensamiento que acabamos de exponer. Veámoslo desde el punto de vista de la trascendencia. Su reflexión en este sentido corresponde a la época del llamado "último Heidegger" ${ }^{36}$; su madurez filosófica. La noción de "trascendencia", tal como se desprende de su obra, puede entenderse en dos perspectivas distintas, que expondremos sucintamente a continuación.

El primer sentido del término derivaría del Dasein (estar allí, en el mundo) heideggeriano; el cual se encuentra en su "estar-más allá-de-sí; y esta presencia "exterior" es, por llamarla de una forma apropiada, trascendente, puesto que significa, en la perspectiva del autor, "el que permanece el tiempo que traspasa" 37.

El segundo tipo de trascendencia que se descubre en su pensamiento es lo que podríamos denominar "trascendencia propiamente tal "(puesto que es el que desarrolla-

No in teresa aquí formular las distinciones y reparos que puede haber en esta clasificación; como si se trata de trascendentales "absolutos" o "relativos".

34 Cf. González Alvarez, A., Tratado de Metafísica, Vol. I: Ontologia. Editorial Gredos, Madrid, 1987, pg. 172ss

35 Ob. cit, pág. 173

36 . En sus últimas obras, Heidegger abandona el plano del análisis existencial, para dedicarse a trabajar directamente sobre problemas ontológicos. Ya en Ser y Tiempo había anunciado que la problemática de carácter metafísico constituía el propósito fundamental de sus investigaciones filosóficas. 
ría la línea abierta por la filosofía tradicional), y está constituida por la llamada "Diferencia Ontológica"; es decir, por el ser en cuanto ontológicamente diferente del ente o predicamental. Es muy conocida la afirmación del filósofo en el sentido de que la metafísica occidental ha olvidado el "ser" (Seinvergessenheit) porque le ha confundido con el "ente" ${ }^{38}$. A partir de este hecho, se hará preciso, afirma, instaurar una nueva filosofía ontología y gnoseología al mismo tiempo- que repare este error, y abra un nuevo cauce al pensamiento.

¿En qué sentido se constituye esta diferencia ontológica? Formular esta pregunta equivale a plantearse la siguiente cuestión: ¿En que trasciende el ser al ente?. Las respuestas a ambas interrogantes llevan - creemos - al significado heideggeriano de trascendencia. En la Constitución Onto-teo-lógica de la metafísica ${ }^{39}$, plantea que la diferencia se verifica ya en el tó on del pensamiento griego, es decir, en "aquello que es"; en la medida en que allí se encuentra "aquello que" (la entidad que ejerce el ser) y, por otro lado, el "es", el ser mismo que dicho sujeto ejerce. Ahora bien, el sujeto que ejerce el ser es el ente; de tal modo que la diferencia entre "aquello que" y "es" es igual a la diferencia que media entre el ser y el ente. En sus propias palabras:

"En la duplicidad de la significación párticipal del ov se oculta la diferencia entre 'siendo' y 'ente'. Esto que, expuesto así, se presenta primeramente como una sutileza gramatical, es en verdad el enigma del ser" ${ }^{40}$.

La proposición radical de la diferencia ontológica es que el ser va más allá del ente; supera al sujeto que lo realiza, y en este sentido lo trasciende, mas no a la manera en que una noción general abarca distintas entidades, pues "es cuestionable que la universalidad del ser sea del género (genus) "1 41 .

Parte de la doctrina tiende a identificar o hacer coincidir la trascendencia que propone Heidegger con la noción escolástica que hemos referido antes, en cuanto el modo omne ens qua ens que se desprende del concepto de ser que propone; otro sector (en general, la analítica) lo vincula con la trascendentalidad kantiana -que veremos a continuación-, en cuanto posibilidad de todo objeto en cuanto objeto. Finalmente, un tercer grupo $\left(\mathrm{Wahl}^{42}\right.$, Mounier) constituido mayoritariamente por los existencialistas-

38 "La esencia del estar presente $y$, con él, la diferencia entre el estar presente y lo presente, permanece olvidada. El olvido del ser es el olvido de la diferencia entre el ser y el ente". Heidegger, Holzwege, Frankfurt, Klosterman, 1952, pág.336

39 Heidegger, Identidad...,pág. 67

40 Heidegger, Sendas perdidas, pág. 317

41 . Heidegger, M., Introducción..., pág. 109 ss

42 Es interesante consignar que este autor distingue en Heidegger los siguientes sentidos de "trascendencia":

a) La trascendencia de la existencia sobre la nada

b) La trascendencia del existente respecto al mundo

c) la trascendencia del mundo respecto al existente

d) La trascendencia del existente con relación a sí mismo, en el movimiento por el cual se proyecta hacia el porvenir.

Wahl, J., Existence Humaine et Tras-cendence, París, 1994 
presenta su idea de trascendencia como algo más radical que los dos sentidos anteriores, puesto que en ellos lo que trasciende no sería verdaderamente el ser, sino el ente (es decir, caerían en el "olvido ontológico" que mencionábamos antes).

A nuestro juicio, la tesis de Rioux ${ }^{43}$ y otros autores, en el sentido de que el esse tomista y el Dasein heideggeriano tienen muchos puntos en común, parece ser bastante probable; o, por lo menos, digna de ser estudiada. En el medio hispanoparlante, es conocida la obra de Echauri, que se pronuncia también favorablemente en este sentido ${ }^{44}$. Por tal motivo, la consideramos aquí como un nuevo planteamiento contemporáneo de lo que hemos llamado "modelo metafísico".

\section{3-El modelo de la filosofía trascendental}

El sentido que hemos esbozado muy superficialmente del término que nos interesa - pues no aspira a más la intención de estas páginas-, sufre una profunda transformación a partir de Kant ${ }^{45}$; concretamente, desde la aparición de la Crítica de la Razón Pura (en adelante, KrV). Se trata de uno de los momentos cruciales de la modernidad filosófica, constituido por la reflexión sistemática y diferenciada en torno a la mediación de la realidad por la libertad y el espíritu, con un distanciamiento explícito de la fundamentación causal, que había sido el centro del pensamiento especulativo precedente. Esta mediación a que hacemos referencia lleva a la distinción (quizás sería mejor hablar de "separación") fundamental entre "razón teórica" y "razón práctica". De momento, sólo trataremos la primera de ellas. La reflexión Kantiana sobre la razón teórica o razón "pura" es lo que deriva en el giro trascendental: cualquier inteligencia de la fundamentación del ente en el ser es precisamente inteligencia; supone al mismo tiempo una inteligencia de esa misma inteligencia, lo que llamaríamos una "autointeligencia" ${ }^{46}$. El giro trascendental significa la estricta correlatividad de la inteligencia y de la realidad. Desarrollaremos esto un poco más.

Si la línea trazada por el pensamiento metafísico tradicional se centra en el esse como núcleo constitutivo y fúndante de toda realidad, la pregunta kantiana por la posibilidad de aprehensión de dicho acto de existir centra inmediatamente el problema de la trascendencia en el plano de la teoría del conocimiento; pero desde una perspectiva gnoseológica distinta de aquella ofrecida por quien sustenta la tesis de una ontología realis$\mathrm{ta}^{47}$ : surge a partir de la duda radical sobre los presupuestos de los que se levantaba la

43 Cf. fundamentalmente Rioux, B., L'Etre et la Verité chez Heidegger et Saint Thomas d'Aquin P.U.F., 1963

44 Véase Echauri, R., Heidegger y la Metafísica Tomista. Editoria Universitaria de Buenos Aires, 1970. Prólogo de Gilson; y El Ser en la Filosofía de Heidegger, Buenos Aires, 1968

45 Para lo que sigue, remito al excelente trabajo de A. Llano: Fenómeno y trascendencia en Kant, EUNSA, Pamplona, 1973

46 Cf. Simons, E., en Conceptos Fundamentales....., voz Trascendencia, pág. 558T

47 La gnoseología escolástica parte de la base de que, al ser las cosas de una determinada manera (esencia); esta forma es permeable al intelecto cognoscente, que la aprehende con verdad lógica (producto y consecuencia de la Verdad ontológica), de tal manera que la esencia del objeto conocido se a nida en la mente del sujeto no a la manera de una representación, sino como existen- 
gnoseología anterior. El "¿Cómo Conocemos?" escolástico se cambia por un "¿Podemos conocer?" En esta perspectiva, lo directamente problemático es ahora lo que antes constituía una afirmación evidente: la aparición del Ser Infinito, clave de la trascendencia medieval. Este planteamiento, y la respuesta que Kant da, marcan el inicio de la transformación en el plano de la metafísica, que caracteriza la filosofía moderna; cuyas consecuencias en el ámbito moral, ético y jurídico son desde luego importantes.

¿Qué significa "trascendencia" para esta nueva concepción?. No se trata, evidentemente, de un concepto secundario, puesto que Kant denomina su propio pensamiento como "filosofía trascendental" 48 ; otorgándole con ello la noción que estudiamos un valor primordial dentro de su sistema. ¿Nos encontramos, sin embargo, ante la misma concepción de la realidad subyacente en la idea de la filosofía anterior? La respuesta a esta pregunta es lo que se ha llamado en filosofía el giro trascendental de la metafísica. Vamos a explicar brevemente esto; para delimitar un nuevo sentido de lo trascendente que escapa por completo al anterior, que ya hemos referido.

El tema de la obra kantiana es, fundamentalmente, el mismo que desarrolla el pensamiento escolástico. Ahora bien, si la metafísica tradicional intentaba averiguar qué es el ente, el intento de Kant radica más bien en determinar si esa pregunta tiene o no sentido. Tal cosa constituiría, en palabras del mismo kant, el paso de una "metafísica natural" a otra, superior, llamada "científica" ${ }^{49}$. ¿Por qué? Porque el paso de lo fenoménico a lo trascendente, tal como se planteaba en la gnoseología tradicional, le parece al filósofo de Königsberg que se apoya en supuestos que no han sido analizados. Su conclusión será que el conocimiento de la realidad es tal, que el sujeto es en cuanto constituye el objeto; y, a su vez, el objeto es en cuanto está constituido por el sujeto. En sus propias palabras:

"El término 'trascendental' se aplica al conocimiento en tanto que se refiere a la posibilidad de conocimiento a priori (anterior a la experiencia). $\mathrm{Ni}$ el espacio ni ninguna determinación geométrica a priori del espacio es una representación trascendental. Solamente puede ser calificado de trascendental el conocimiento de que estas representaciones no tienen origen empírico y la posibilidad de que, a pesar de ello, puedan referirse a priori a objetos de la experiencia. La aplicación del espacio a objetos en general podría ser asimismo trascendental, pero cuando se confina únicamente a objetos de los sentidos, es empírica. La distinción entre lo trascendental y lo empírico pertenece, pues, solamente a la crítica del conocimiento, no a las relaciones entre este conocimiento y sus objetos" ${ }^{150}$.

Así también:

"Llamo 'trascendental' a todo conocimiento que se ocupa no tanto de los objetos, como del modo de conocerlos, en cuanto este modo es posible a priori. El sistema de tales conceptos puede ser llamado filosofía trascendental" ${ }^{151}$.

cia intencional; en tanto inhiere a su forma substancial como forma accidental.

48

$\operatorname{KrV}, A 12 / B 25$

$49 \quad K r V, A 13 / B 27$

$50 \quad K r V, A 565 / B 81$

51 Ibid. 
El sentido de la expresión "trascendental" se vincula entonces con la idea de "posibilidad del conocimiento" que mencionábamos antes como piedra angular del sistema kantiano; en el sentido de que la investigación filosófica jamás se limita a lo simplemente "dado" (el fenómeno), sino que aspira y busca alga más; una realidad que lo trascienda.

Entonces: si la trascendencia propuesta por la filosofía pre - kantiana se afirma (con los matices y soluciones que se quiera en cada autor en particular) en la línea del ser de las cosas; suponiendo su cognoscibilidad, la solución de la filosofía crítica significa un replanteamiento total del problema, poniendo el quid de la cuestión en si es posible o no trascender cognoscitivamente (ir más allá) del fenómeno. De aquí el sentido de las expresiones "Analítica trascendental", deducción trascendental", "lógica trascendental", etc. Como sabemos, la respuesta kantiana sobre el conocimiento supra-fenoménico se centra en la subjetividad del aprehendente; hasta el punto de que la realidad objetiva y exterior al sujeto parece tener su fundamento en la "configuración permanente de la actividad cognoscitiva" $" 52$.

Es preciso distinguir, sin embargo, lo "trascendental" de lo "trascendente". Lo primero significa, para Kant -como ya hemos apuntado-, aquello que hace posible el conocimiento de la experiencia y no va más allá de la experiencia; mientras que lo segundo se refiere a lo que se encuentra más allá de toda experiencia (por tal motivo habrán de rechazarse las ideas trascendentes; mientras que deben sin duda aceptarse los principios trascendentales, en el sentido expuesto antes) ${ }^{53}$.

Esta transformación gnoseológica de la metafísica tiene una aguda resonancia especulativa en el pensamiento de Wittgenstein; probablemente el responsable más directo del llamado "giro lingüístico" que ocupa la historia reciente del pensamiento especulativo occidental. La continuación de la tesis kantiana en clave analítica es la siguiente ${ }^{54}$ : así como la crítica del conocimiento sustituye la teoría del ente en cuanto tal, la teoría del lenguaje viene a hacer -a su vez- otro tanto con la crítica del conocimiento, puesto que "la formulación de estos problemas (los filosóficos) descansa en la falta de comprensión de nuestro lengüaje" ${ }^{155}$.

Con independencia de la posición que se quiera adoptar al interpretar a Wittgenstein, a saber: afirmar que su obra nos lleva una suerte de "metafísica del silencio" en la que no es posible decir nada; o bien que, por el contrario, estimar que "lo que puede ser expresado, puede ser expresado claramente" ${ }^{56}$, lo cierto es que la transformación

52 Llano, Metafísica ..., pág. 19

$53 \mathrm{KrV}, \mathrm{A} \mathrm{565/B} 351$

$54 \quad{ }^{54}$ Sigo en esto opinión de Llano (Met. y Lengüaje, pág. 15 ss) que se basa a su vez en los trabajos de Geach, Anscombe, Putnam y otros. La raíz kantiana de este giro lingüístico es puesta de relieve por Stenius ("Wittgenstein's Tractatus", Blackwell, 1964), y rebate la impresión, atribuida a la influencia de Russell, de que la obra del filósofo vienés se encuentra en la línea del empirismo de Hume.

$55{ }^{55}$ Wittgensteln, L., Tractatus Logico-Philosiphicus. Schriften, Prólogo. Suhrkamp, Frankfurt, 1960. Pág. 9 
lingüística que propone lleva el problema de la trascendencia al significado de las palabras del lengüaje. Tampoco interesa aquí el problema de si este giro tiene su origen en la filosofía crítica o, por el contrario, hunde sus raíces en el empirismo. En nuestra opinión, el vínculo entre el criticismo kantiano y la analítica es hoy en día casi evidente, pues el paso "realidad - conocimiento de la realidad-expresión de dicho conocimiento" es perfectamente lógico y consecutivo. La crítica como duda sistemáticamente, una vez iniciada, no se detiene, y acaba por curvarse sobre sí misma.

Esta nueva noción de trascendencia que apuntábamos puede formularse así: las proposiciones con sentido (es decir, aquel lenguaje que sólo es susceptible de un análisis exhaustivo y unívoco) están compuestas por nombres que significan a su vez objetos; de tal manera que dichas proposiciones con sentido constituyen la condición de posibilidad de esos mismos objetos. Por ello, afirmará más adelante que "la lógica no es una doctrina, sino un reflejo del mundo", y es "trascendental" 57 , porque no es la realidad la que constituye el lenguaje, sino el conjunto de las proposiciones con sentido el fundamento de toda realidad, en tanto que "los límites del lenguaje son los límites del mundo" 58 .

Tenemos, así, trazadas muy esquemáticamente las dos líneas principales de especulación filosófica que marcan el pensamiento occidental, de las que podemos colegir dos conceptos distintos de trascendencia. Si hasta Kant el problema metafísico de la trascendencia se ubicaba en la línea de un ser "más allá del mundo"; desde él se traslada a la línea de un ser "más allá del sujeto". Veamos de qué modo se concretan estos planteamientos, de cara al aspecto estrictamente jurídico de la cuestión.

\section{4- Trascendencia y razón práctica}

Si el problema de la trascendencia metafísica se reduce a la existencia o inexistencia de entidades subsistentes con independencia del sujeto que las conoce ( $y$, por lo tanto, a la existencia o inexistencia de un principio plenamente actual que les conceda tal virtualidad); la pregunta por la trascendencia en el ámbito de la razón práctica puede, a nuestro juicio, formularse en los siguientes términos:

¿Existe algún principio en el orden del obrar que sea ajeno y anterior a la voluntad libre y autorreferencial del sujeto que actúa?

Toda posición metafísica importa una solución derivada en el ámbito de la praxis, puesto que la condición humana no puede conformarse con explicaciones que se desentiendan de ella. Si el hombre es un ser material, dotado de movimiento y voluntad, su pensamiento abstracto ha necesariamente de fundamentar el plano de su acción; de su moral y de su arte. El sujeto que reflexiona no se agota en la mera reflexión -aunque se la repute la más alta de sus actividades-; sino que es una entidad tendente, en movimiento; y este movimiento supone en radicalidad todo su ser, no solo uno o algunos de sus aspectos y parcialidades (sin perjuicio de que, una vez que el ser humano haya al-

57

58
Tractatus, 6.13

Tractatus, 5.6 No es objeto de este análisis el problema de si las Investigaciones Filosóficas cambian o no esta concepción. El giro lingüístico queda abierto en los términos que propone el Tractatus; cuya vinculación con el planteamiento kantiano se hace patente. 
canzado su fin último, la facultad cualitativamente más alta será, ahora en todo su esplendor, la inteligencia). La ausencia absoluta de una normativa sobre el obrar del hombre conduce a un estado de inmovilidad radical y fundamental, en el cual la pregunta por la causa de los actos se torna vacía (quien afirma que la regla moral es totalmente inmanente a su voluntad, afirma en definitiva que la norma implícita es la satisfacción caprichosa de sus deseos circunstanciales; pero esta opción ya constituye per se, formalmente, un cierto precepto).

Así pues, los dos posicionamientos de carácter ontológico que hemos referido antes conducen a propuestas distintas de solución para explicar y fundar la praxis humana; propuestas éstas que suponen, en cada caso, no ya un concepto diferente de trascendencia, sino una opción lisa y llana por lo inmanente o lo trascendente tal como lo hemos descrito (puesto que hemos delimitado el problema metafísico del concepto al origen de la existencia de las cosas: o bien éstas existen en sí mismas, en cuyo caso son trascendentes al sujeto; o es éste quien las pone en el mundo, de tal manera que le son inmanentes. Y lo mismo se diga para su conocimiento o expresión mediante el lenguaje) ${ }^{59}$.

Expondremos brevemente la solución que cada teoría ofrece en torno al tema de la trascendencia moral.

\section{5-Razón, naturaleza y fin}

La idea de "razón práctica" debe entenderse, en Aristóteles y Tomás de Aquino, como contraste de la expresión "razón teórica" o "razón especulativa"60. Los escolásticos dieron a la operación de la razón teórica el nombre de speculatio (que proviene de speculum, espejo) ${ }^{61}$. La voz designa la acción y efecto de speculare (speculor), que se refiere también al sentido de observar, y especialmente, observar desde cierta. altura o distancia. En esta perspectiva, por lo tanto, el conocimiento teórico debe entenderse como equivalente al conocimiento especulativo.

Ambas palabras - teoría y especulación - sirven para designar, en el contexto tradicional de la filosofía, aquella actividad del intelecto cuyo fin es la mera cognitio veritatis; aquel tipo de conocimiento cuyo único objeto es alcanzar la verdad (conocimiento éste que se reputa en estas tesis, como hemos visto antes, de suyo alcanzable) y reflejarla en ese mismo acto de conocer. Este es el tipo de razón propio del ámbito metafísico, del cual se predica con primaria y fundamental inmediatez.

59 Insisto en que cada una de estas tesis, el realismo y el idealismo extremos, tienen variantes y matices, encarnados por autores y corrientes, que no son del caso tratar aquí. Sólo nos interesa describir la actitud general de cada teoría; de la cual participan más o menos todas las vertientes que en ellas se fundan: no se puede ser una cosa o la otra sin poner el énfasis en el principio que se defiende; aunque cada reflexión presente diferencias a partir del mismo origen.

Met.,Z,1,1025b 18-28

61 También contemplativo. Hay que tener en cuenta, eso si, que en un principio esta relación de "teoría" y "contemplación" adquirió un sentido religioso (contemplor - templum). Ello tendría como consecuencia que contemplativo vendría a designar el hecho de encontrarse en comunidad dentro de un templum; con la consiguiente posición de algo en común entre los miembros de la comunidad. 
La diferencia con la "razón práctica" se verifica por lo tanto en el orden del fin ${ }^{62}$. El llamado "intelecto práctico" es estimulado por el objeto del apetito; no por el conocimiento de las esencias o del ser, aunque lo suponga. Tomás de Aquino y los escolásticos tradujeron la expresión griega por intellectus practicus y ratio practica (u operativa) ${ }^{63}$. El mismo Aquinate expresa la diferencia entre una y otra, afirmando que la primera se limita a aprehender las cosas; mientras que la segunda no sólo aprehende, sino también causa. ${ }^{64}$.

De esta diferencia fundamental que hemos señalado, fluye tanto en Aristóteles como en Tomás de Aquino la siguiente consecuencia: la razón práctica sigue al apetito; mas como lo que apetece siempre es un bien ${ }^{65}$, resulta que el objeto de esta función intelectual es, precisamente, distinguir lo bueno de lo malo (a partir de lo verdadero/falso), con la consiguiente apetencia o rechazo por parte de la voluntad. La elaboración ética de Aristóteles y del Aquinate es, según esto, abiertamente teleológica: pues la acción se considera buena no en cuanto a sí misma, sino en cuanto conlleva el bien del hombre (y es "mala" en la medida en que lo aleje de este bien); pues "fin" y "bien" se constituyen como términos muy vinculados ${ }^{66}$. Hay, como es lógico, distintos tipos de bienes, que corresponden a diferentes clases de saberes; pero hay un bien que se desea por sí mismo, al cual se ordena la consecución de todos los bienes intermedios: la felicidad $^{67}$. Este bien supremo es el que constituye el objeto de la "ética", en tanto ciencia que le estudia; y de la "moral", entendida como una cierta medida normativa de la perfección de los actos respecto o en relación al fin final del hombre.

Este bien -apunta Aristóteles- no es matemático ni exacto, sino que se constituye a partir de las obras humanas ${ }^{68}$. Además, continúa el Estagirita, matemáticas y ética poseen otra gran diferencia: la primera se inicia en principios generales, y llega desde ellos a conclusiones; la segunda se inicia, en cambio, en conclusiones, y se desarrolla hasta alcanzar principios generales ${ }^{69}$. Si de las conclusiones pueden lograrse principios

63 Sum.Teol., I, q.LXXIX, a.11

64 Sum. Teol, II-II', q.LXXXIII: "Ratio vera practica est non solum aprehensiva, sed etiam causativa" Véase también Sententia Libri Ethicorum, II, cap.2, 16-21

65 Aristóteles, Et a Nic., 1094a 1-3: "Toda obra y toda elección parece apuntar a algún bien; por lo que el bien ha sido definido con acierto como aquello a lo que tienden todas las cosas" También Tomás de Aquino: "Bien es aquello hacia lo que todas las cosas tienden". Sentencia Libri Ethicorum,i cap. 1, 148-164 La definición originaria de "bien", en Tomás de Aquino, no es moral, sino metafísica: "bien final de una realidad es aquello que perfecciona su ser"

66 La razón práctica o praxis debe distinguirse de la techné y de la poiesis. Mientras las dos últimas tienen por objeto el bien de la obra, con independencia del sujeto que la realiza; la praxis se refiere al bien del hombre, e intenta dirigir sus actos hacia su fin, que es su bien.

67 Según Aristóteles, la felicidad debe ser una actividad que desarrolle la peculiaridad del hombre: la razón. Sólo esta actividad llevará a la naturależa a ser "ella misma", alcanzando por lo tanto su fin o bien último. Cf. Et. Nic., Libro I ss. También Tomás de Aquino, Sent. Lib. Et., l, cap. $18,150-155$ 
generales, se puede concluir que existen ciertos mecanismos en el hombre que se repiten en todos los individuos; de tal modo que existen en ellos tendencias e inclinaciones propias de su esencia ("naturaleza", en cuanto con seres que se mueven por sí mismos), a las que debe sujetarse para desarrollar una vida moral que le permita alcanzar su fin. Esta noción del acto moral ajustado a reglas que se basan en un contenido de tipo natural, propio de todos los hombres, y obligatorio para llegar al fin propuesto, excluye la idea de la voluntad moral autorreferencial; y por ello la categoría moral de los actos puede reputarse como trascendente; en cuanto tiene en cuenta una norma exterior. En este sentido, lo trascendente se identifica con lo heterónomo.

En Tomás de Aquino se reproduce esta posición ${ }^{70}$, aunque cualitativamente superada por el contexto metafísico propiamente tomista, que privilegia, en la línea de la actualidad, el esse sobre el ens; la existencia sobre la forma. Ello se comprende a partir de la distinción de los diversos grados o tipos de "verdad", jerárquicos entre sí, que plantea el sistema tomista, y que Aristóteles no podría haber propuesto a partir de su metafísica de la substancia.

La razón teórica se manifiesta como propter contemplatio veritatis; mientras que la razón práctica se estructura como propter operationem. La expresión de esta razón práctica es el precepto (praeceptum) ${ }^{71}$, cuyo contenido es racional, pero extrae su carácter de mandato de la voluntad. La finalidad de la obra del sujeto, que constituye el objeto típico de este tipo de razón, halla -para Tomás de Aquino- su punto culminante en la virtud de la prudencia, en cuanto ésta deriva en el último precepto práctico concreto, que permite actuar rectamente -es decir, distinguiendo el mayor bien de entre los presentados a la inteligencia -en cada caso particular ${ }^{72}$.

De este modo, la inteligencia especulativa o teórica descubre las esencias de las cosas, pues las cosas son algo, con independencia de la subjetividad del aprehendente. Acto seguido, la razón práctica, de entre todas las entes del mundo, halla que el hombre posee un cierto modo de ser, llamado esencia o naturaleza humana, del cual fluyen unos contenidos determinados que, por virtud de una voluntad legisladora ${ }^{73}$, se transforman en mandatos morales heterónomos de la voluntad arbitraria del sujeto; y que deben ser respetados para que dicho sujeto alcance su fin propio, propuesto y diseñado en su misma e íntima forma de ser.

Etica a Eudemo, 1216b 32 ss Esto es igual que afirmar que los principios éticos que formula la razón práctica provienen, en último término, de la observación y la experiencia, en tantoText of Footnote que se originan en la realidad humana y pueden en consecuencia ser comparados y sopesados en un caso y en otro.

Sobre la fidelidad de la tesis tomista al planteamiento aristótelico,.Cf Jaffa, H.V., Thomism and Aristotelianism. A Study of the Commentary by Thomas Aquinas on the Nicomachean Ethics, Chicago, 1952 passim

Sent. Lib. Et., VI, cap. 9, 43-55

Cf. Melina, L.; la Conoscenza Morale, Citta Nuova Editrice, Roma, 1987, p. 35

Cf. Vitoria, F., Reelección de aquello a que está obligado el hombre cuando llega al uso de razón, II, n.9, pág. 1353, en Obras de Francisco de Vitoria. Relecciones Teológicas, Biblioteca de Autores Cristianos, Madrid, 1960 
El bien final es, en esta concepción, la perfección del sujeto según su propia naturaleza ${ }^{74}$, y precisamente por ello pueden estos autores fundar la trascendencia de dicho bien respecto de la voluntad arbitraria o vacía de contenido: si la razón descubre la naturaleza como concepto, y perfila en forma de contenidos sus inclinaciones y tendencias, la voluntad recta no es otra cosa que la búsqueda de esa tal verdad desde la perspectiva del bien, mediante la interiorización del mandato que deriva de la norma que proviene de la naturaleza, también llamada "ley natural" ${ }^{75}$.

Lo característico del planteamiento tradicional es, por tanto, que la norma o precepto moral se funda, en consecuencia -y en última instancia-, en el ser de las cosas, que es reconocido y aceptado por la inteligencia aprehendente (verdad lógica); y al cual la voluntad debe adherirse si desea obtener su fin último, aunque puede no hacerlo en el orden de los hechos ${ }^{76}$.

Para terminar, hay que tener presente que, en esta teoría, la norma moral se constituye, en un sentido primario, como algo trascendente respecto de la voluntad; pero en otro sentido, secundario, puede simultáneamente reputarse como inmanente en relación con la misma facultad. Es trascendente en el sentido que hemos consignado antes: el contenido de la norma no procede de la voluntad subjetiva del individuo, y en consecuencia la moral es heterónoma a la voluntad; mas es inmanente si se tiene en cuenta que es precisamente una voluntad la que constituye en mandato un determinado contenido (pues es tesis escolástica que sin mandato no hay ley; pero todo mandato proviene forzosamente de una voluntad que lo constituye en tal); $y$, en el plano del individuo concreto, es la propia aceptación volitiva del sujeto la que determina la elección de ese contenido y no otro en el orden de la acción, y la que produce en definitiva el resultado eficaz; todo ello dentro de un tiempo y espacios determinados.

\section{6-Razón práctica a priori: el imperativo categórico}

La respuesta kantiana al problema de la acción parte de la barrera infranqueable entre razón teórica y razón práctica como funciones distintas; ubicándose así en el polo opuesto de la tesis tradicional, que, como hemos visto, aseguraba la expedita transitividad de la primera a la segunda. Una cosa tienen, eso sí, en común ambas facultades: cualquier clase de razón -sea teórica o práctica-sólo puede moverse legítimamente con

75 "La ley natural no es otra cosa que la concepción naturalmente incita en el hombre, por la cual se dirige éste a obrar de módo conveniente en sus acciones propias, ya le competan dichas acciones por su naturaleza genérica....ya por su naturaleza específica.." Tomás de Aquino, In IV Sent, d. 33, q. 1 a.1 Vide también Sum. Teol., I-II, q.10, a.I: "Es necesario que el principio de los movimientos voluntarios sea algo naturalmente querido; y esto es el bien común, al cual tiende naturalmente la voluntad, como cada potencia tiende a su propio objeto, y también al mismo fin último... y de un modo general todas aquellas cosas que convienen al hombre según su naturaleza"

76 Este es el fundamento de la libertad, tal como la concibe Tomás de Aquino: aún cuando la recta inteligencia muestre a la voluntad el bien más alto, no por ello esta facultad está obligada a elegirlo. Por este motivo, la libertad es definida como "una cierta capacidad de elegir" 
independencia de la experiencia sensible; y en ese sentido, tanto la una como la otra constituyen tipos "puros".

Proclama Kant, además, el estatuto absolutamente pre-científico de la ética, pues hacerla depender del conocimiento sería equivalente a conceder privilegios morales al hombre letrado sobre el iletrado, sin considerar su cualidad primaria de sujetos ( $y$ sabemos que la praxis no puede venir del conocimiento de la existencia de Dios, pues en esta tesis no hay certeza alguna sobre ella). Esta ética que no pasa por el conocimiento de las esencias de las cosas es forzosamente autónoma; como expresión de una entidad racional para el cual tiene sentido la determinación de su conducta "por la determinación de su conducta".

La analítica de la razón práctica estudia, afirma Kant, los principios a priori de la ética; que no se apoya a su vez en ningún principio teórico, sino que parte de la base de la moral como simple faktum; un hecho. Este punto es también una diferencia con la razón teórica:aquella, si bien es verdad que contenía las condiciones de posibilidad de todo conocimiento, las contenía sólo en la medida en que era posible acceder a una institución sensible ( $y$, en consecuencia, sólo para objetos de la experiencia); mientras que la norma moral, en cambio, proporciona de entrada un hecho que los datos del mundo sensible ni los de la razón pura pueden explicar: una ley ${ }^{77}$. Esta norma o ley -y éste es el punto central de la tesis-, en cuanto constituye un hecho puro de la razón, no requiere ser deducida teóricamente; como tampoco sujetarse a demostración por parte de la experiencia sensible. La ley -como norma de conducta- es algo que se impone por sí misma. He aquí el texto:

"La ley moral es dada, por así decirlo, como un hecho de la razón pura, del cual nosotros tenemos consciencia a priori y que es cierto apodícticamente, aún suponiendo que no se pueda encontrar en la experiencia ejemplo alguno de que se haya seguido exactamente. Así, pues, la realidad objetiva de la ley moral no puede ser demostrada por ninguna deducción, por ningún esfuerzo de la razón teórica, ni puede tampoco ser confirmada por la experiencia y demostrada así a posteriori; sin embargo, se mantiene firme sobre sí misma" ${ }^{78}$.

Si esta ley o norma moral se fundamenta desde sí misma, es fácil comprender que su principio o razón más íntima es el concepto de "deber", al cual el mismo Kant lo define como "la necesidad de realizar una acción por respeto a la ley" ${ }^{79}$. Como afirma Colomer, este deber "no es un nuevo hecho moral, sino la expresión del hecho moral originario que se manifiesta aquí como un imperativo, es decir, como una regla que impone a la voluntad la obligación de llevar a cabo una acción, al margen de las inclinaciones de la sensibilidad, del sentimiento de placer o desagrado, de los deseos egoístas y del amor

Crítica de la razón práctica (en adelante, $K p V$ )., Utilizo para estos efectos la traducción casteIlana de E. Miñana y M. García Morente. Espasa Calpe, Madrid, 1975, pág. 84

Kpv., pág. 94

79 Fundamentación de una Metafísica de las Costumbres. Edición de la Academia de Berlín, volumen IV, pág.414. Utilizo también la traducción castellana de M: García Morente, en Espasa Calpe, Madrid, 1932, pág. 55. Que la idea de deber derive de la naturaleza, es algo completamente impensable en esta teoría. En el mundo de lo natural, las cosas son simplemente lo que son, sujetas siempre a la ley indeclinable de la causalidad. 
propio, por el único motivo del respeto debido a la ley ${ }^{180}$. Ahora bien, esta ley tiene una particularidad: es un principio práctico (entendido por tal aquel que propone una determinación universal de la voluntad) de carácter objetivo; es decir, estima o supone una condición que es reconocida como legítima por todo individuo racional; por lo tanto, con validez absoluta para todo ser humano en cualquier circunstancias ${ }^{81}$.

¿Cuál ha de ser, sin embargo, el contenido de dicho imperativo? Kant responde que, precisamente, para ser universal, ese contenido debe ser por fuerza indeterminado. Lo explica el filósofo regiomontano en los términos siguientes:

"El principio de la propia felicidad, por mucho que se use en él del entendimiento y de la razón, no contendría para la voluntad ningunos otros fundamentoș de determinación que los que son conformes con la facultad inferior de desear, y entonces, o no hay facultad superior alguna de desear, o la razón pura que tiene que ser por sí sola práctiça, es decir, tiene que poder determinar la voluntad mediante la mera fórmula de la regla práctica, sin la suposición de ningún sentimiento, por tanto, sin representaciones de lo agradable o desagradable como materia de la facultad de desear, materia que siempre es una condición empírica de los principios" ${ }^{82}$.

El punto que distingue, para Kant, una facultad superior o inferior de desear, es el hecho de que la voluntad sea determinada a posteriori por el sentimiento de dolor/placer (en cuyo caso, será "inferior"); o a priori por la razón pura (superior). Ahora bien, ya ha afirmado antes ${ }^{83}$ que toda regla práctica material (es decir, con contenido) fundan la determinación de la voluntad en la ya mencionada facultad inferior de desear, por lo tanto la norma que procede de la facultad superior, para ser realmente propia de ella, debe carecer de contenido; se determinará por su mera formalidad. El ser racional, en consecuencia, a la hora de formular su ley moral, deberá pensarlas como principios tales que supongan la determinación de la voluntad del sujeto no por su materialidad o contenido, sino por su mera y estricta formalidad ${ }^{84}$. La formulación de esta ley es el "imperativo categórico" ${ }^{85}$, cuya única determinación en su carácter de ley universal, necesaria e indeterminada.

Vemos por lo tanto que la voluntad, tal como se encuentra presente en este imperativo moral, se halla libre y al margen de toda condición empírica; de tal modo que la razón pura se constituye en la instancia verdaderamente legisladora, y absolutamente autónoma:

Colomer, E, El pensamiento alemán de Kant B Heidegger, Editorial Herder, Barcelona, 1986, volumen I (Kant), pág. 210

81 Esto es lo que diferencia, en el sistema kantiano, entre los conceptos de "ley" y de "máxima"; pues la segunda carece de este reconocimiento general, y sólo vale para el caso concreto de un sujeto en determinadas circunstancias. La máxima es, por lo tanto, un principio práctico; pero no imperativo. Cf. KpV, adición citada, pág.39 (Ed.Ac.Berlín, I/1,c.1,pág.19)

$K p V, p .50$

83

$K p V, p .45 s s$.

$84 \quad K p V, p .56$

85 "Obra de tal modo, que la máxima de tu voluntad pueda valer siempre a la veż, como principio de una legislación universal" KpV, p.63 
"La autonomía es aquella propiedad que la voluntad posee de constituir ella misma su propia ley (moral), con independencia de todos los objetos del querer. El principio de la autonomía consiste, en consecuencia, en elegir siempre de tal modo que las máximas de nuestra elección sean comprendidas como leyes universales en este mismo acto de querer........

Y continúa un poco más adelante:

Que el principio de la autonomía de la voluntad sea el único principio de la moralidad se explica por el análisis de los conceptos de la moralidad. Pues se muestra por ello que el principio de la moralidad ha de ser un imperativo categórico, y que éste no manda ni más ni menos que la misma autonomía" ${ }^{86}$.

No hay lugar a dudas sobre el problema de la trascendencia moral en el planteamiento kantiano al menos, tal como hemos expuesto la idea de trascendentalidad/inmanencia al principio de este apartado: es decir, como autonomía o heteronomía de la voluntad al momento de orientar su acción a la finalidad propia del sujeto. Se ve aquí claramente cómo la pregunta por la realidad, que en la tesis escolástica se verificaba en términos de experiencia, se plantea aquí en clave de libertad y autonomía; como interrogación por la posibilidad de autodeterminación voluntaria y libre, que no extrae su fundamento sino de sí misma.

\section{Concepto de trascendencia y el Derecho}

El problema de la trascendencia o inmanencia en perspectiva jurídica se plantea, como es lógico, a continuación de la respuesta que se haya dado al mismo punto en el ámbito moral. En la primera tesis (la escolástico-tradicional), tal cosa se debe al carácter finalista del planteamiento, que entiende todas las finalidades del hombre encadenadas ( $y$ por lo tanto, médiales) hacia un único y absoluto fin final que es, a todas luces, la fuente $y$ el origen de toda trascendencia; mientras que en la segunda (el pensamiento crítico positivista), la regulación de las libertades individuales constituye un valor en sí, propio e indisoluble de la norma misma; la cual constituye un valor per se, en cuanto determina la pervivencia del orden y la seguridad en una comunidad determinada. Esto es fácilmente comprensible, si se tiene en cuenta la nota formalista de esta teoría. Bobbio expresa muy bien esta identificación de "norma" y "fin" cuando se refiere al denominado "positivismo ético"87.

Es preciso tener en cuenta, antes de delimitar el campo sobre el que queremos tratar el concepto de trascendencia jurídica, que partimos del supuesto, generalmente aceptado en la doctrina, de que el problema del derecho antecede al problema de la justicia ${ }^{88}$. No vamos a hablar aquí, por lo tanto, de la teoría de la justicia; sino a intentar referirnos a si el objeto de ella se constituye en la vida jurídica por una voluntad, o depende en cambio de factores externos e independientes de ella, a los cuales ésta debe plegarse para actuar, consiguientemente, en justicia.

86 Kant, Fundamentación..., p. 97 ss.

87 Bobbio, N., II positivismo giuridico, Giappichelli, Turin, 1979, p. 265 ss. 
Así las cosas, creemos que el planteamiento general del problema de la trascendencia jurídica tiene un punto central y tres aspectos o consecuencias derivadas. Este punto central es, como ya hemos insinuado, si la vida jurídica emana o no, en su totalidad o en parte, de la voluntad humana considerada de manera autorreferente. Este contenido genérico se especifica de la siguiente forma:

a- ¿Es lo suyo de cada individuo (su derecho) algo que se constituye en tal por la voluntad del legislador expresada en una norma jurídica? ¿O bien esos derechos dependen de elementos y contenidos anteriores a la voluntad?

b- ¿Es la ley positiva una norma que extrae su contenido de su simple y llana formalidad, o depende éste de factores que superan el simple mandato y se apoyan en notas referenciales?

c- ¿Es el debitum de la ley positiva (el deber o deuda frente al derecho), algo que se fundamenta en la propia norma -en cuanto existente-, o se encuentra en tensión hacia notas supralegales que pueden, en determinadas circunstancias, extinguir esa deuda si la norma escrita no se adecúa a ellas?

Este último punto del problema es el que resalta el profesor Javier Hervada en los términos siguientes:

"¿Qué significan, en definitiva, la inmanencia y la trascendencia en el derecho? Todo se resume en el valor último del debitum del derecho o de la imperatividad de la ley. El carácter de deuda del derecho, y el imperium de la ley, en suma, el deber inherente al fenómeno jurídico, ¿tiene su último fundamento en el hombre o en Dios?. ¿Por qué debe el hombre, en última instancia, dar a cada uno lo suyo y obedecer las leyes? En el bien entendido que dar a cada uno lo suyo y obedecer las leyes se resumen en dar a cada uno lo suyo, pues con la obediencia a la ley que es la justicia legal- se da a la sociedad lo que a ésta corresponde en su relación con el ciudadano'89.

Las dos posiciones metafísicas que hemos desarrollado suponen también una explicación para el fenómeno jurídico; derivada ciertamente de sus respectivas tesis en el plano moral. A ello dedicaremos la ultima parte de estas notas.

\section{8- Realismo jurídico y iusnaturalismo}

No es muy difícil extraer las conclusiones que se deducen, en el terreno jurídico, de un planteamiento metafísico-realista como el que hemos desarrollado antes ${ }^{90}$. Si la realidad metafísica es algo a lo cual el sujeto se pliega, sin determinarla actualmente, en su existencia o esencia, a través de su propia subjetividad individual, resulta en definitiva que la distinción entre "norma moral" y "norma jurídica" radica causas externas (como

Hervada, J., "Inmanencia y Trascendencia en el Derecho", en XXV Reuniones Filosóficas, Universidad de Navarra, Pamplona, 1991, volumen I, pág. 416.

90 Casi no hace falta indicar que el adjetivo "realista" se aplica en estos términos a una concepción que reconoce una realidad metafísica exterior al sujeto; lo cual se traduce, en clave jurídica, como la determinacion objetiva del derecho de cada hombre en virtud de lo que es, y del papel que ocupa en la comunidad. 
la coacción y el consenso ${ }^{91}$ que requiere una norma positiva), que en nada afecta a la naturaleza de dicha ordenación, pero no en el concepto mismo de norma; pues toda disposición que rija la conducta del hombre tiene en última instancia la misma fuente y el mismo contenido. La visión realista del mundo es, en este sentido, perfectamente coherente en cada uno de los planos en los que actúa.

Tal cosa se entiende mejor si se tiene en cuenta lo siguiente: el hombre es, en la concepción tradicional, una criatura que tiende a un fin natural, inscrito en su forma de ser (que le es propia en "cuanto humano, y que puede conocer mediante la razón natural). Como hemos visto antes, la bondad o maldad de los actos del individuo derivan su calidad de tales a partir de ese fin, en cuanto las acciones alejan al sujeto de éste o, por el contrario, le acercan a él. Este orden "natural" es, al mismo tiempo, parte o participación de una cierta ordenación universal; por cuanto todos los seres del mundo provienen ex nihilo de una misma causa última plenamente inteligente, que los dirige hacia este fin de modo consciente (en el caso de los seres inteligentes) o inconsciente; si se trata de substancias sin posesión cognoscitiva de su finalidad intrínseca ${ }^{92}$.

En esta tesis subyace, como es evidente, la identidad fundamental de la causa eficiente y la causa final en una misma entidad máximamente trascendente.

Ahora bien, la vida en sociedad constituye, según esta misma norma natural (usado aquí en el sentido de "necesario"), el espacio propio en el que los seres humanos alcanzan las condiciones de máxima realización material y espiritual que su personalidad requiere. Esta finalidad social primaria se denomina, còmo sabemos, "Bien Común". Sin embargo, uno de los elementos constitutivos de este bonum commune es la ordenación de las partes que conforman esa sociedad; de modo que el espacio vital de cada individuo pueda ejercerse sin conflicto sobre su propia persona, y los bienes que son de todos puedan también disfrutarse con el adecuado concierto, que asegure la justicia y la paz en el entramado social ${ }^{93}$. Ello exige también que las diferencias y conflictos que puedan plantearse entre los miembros de la comunidad sean zanjadas de una manera objetiva; sin pasar por la voluntad particular de cada interesado; forzosamente parcial a la hora de discutir su propia conveniencia. Esta regulación objetiva es lo que se denomina "ordenamiento jurídico" o simplemente "Derecho", expresado por la ley positiva. Esta norma jurídica positiva no es, sin embargo, un producto arbitrario de la voluntad legislativa. Es convencional sólo en la medida en que determinados legisladores, hic et nunc, redactan tal o cual fórmula legal en una sociedad determinada en el espacio y el tiempo ${ }^{94}$;

91 Al hablar de consenso, nos referimos al mínimo grado de aceptación que debe tener una norma jurídica para ser eficaz dentro de una comunidad; no al acuerdo de voluntades como fundamento del carácter último de norma.

92 La ley natural es definida por Tomás de Aquino como la participación de la Ley Eterna en la criatura racional. No se trata de dos leyes distintas; sino de modos de ser diferentes de una misma ordenación; según reside en la mente de la Causa Primera, o en el sujeto que la realiza. Cf. Sum. Teol., I-II, q.94, a.1

93 Cf, Koninck, Ch, De, De la primacía del Bien común contra los perșonalistas, Ediciones Cultura Hispánica, Madrid, 1952, p. 25 ss

94 De la misma manera en que una sociedad concreta tiene raíz en la sociabilidad humana; pero que los hombres concreten ésta comunidad ( $y$ no otra) en un momento determinado es un he- 
más todo orden debe entenderse en esta concepción como partícipe del orden supremo de la Creación, y no puede en consecuencia ir en su contra, so pretexto de constituirse inmediatamente al margen de ese orden; y por lo tanto en el terreno del mero factum ${ }^{95}$. Por ello una regla jurídica puede estar vigente en una sociedad y no constituir, en propiedad, una "ley", desde esta perspectiva.

Hay por lo tanto una parte de ese contenido natural del hombre, o ley natural, que se dirige a regular las relaciones de los hombres en sociedad. Este aspecto se denomina "Derecho Natural", y se funda en última instancia en que los seres humanos son una naturaleza específica, que participa en el orden universal de todos los seres que buscan su perfección a través de la comunidad de hombres, en la cual dicha naturaleza o. forma de ser debe ser respetada ${ }^{96}$. Aquel aspecto de la ley natural que se refiere a la vida en comunidad funda completamente el contenido y carácter de la ley positiva, que proviene directamente de la natural por dos medios: conclusión y determinación ${ }^{97}$.

La norma moral personal parece, en esta perspectiva, constituir entonces un espacio simplemente interno del sujeto, ajeno por completo a la vida jurídica; donde sólo tendrían relevancia las reglas que puedan efectivamente -fácticamente- redundar en favor o en contra de los otros miembros de la comunidad. Esta consideración es la que, como sabemos, lleva a algunos a separar por completo el ámbito moral del jurídico ${ }^{98}$. Tal posición, si se absolutiza, reduce la tesis tomista tradicional a contenidos que éste no llega a afirmar ${ }^{99}$. Si bien es verdad que la norma moral personal afecta sólo a la perfección del sujeto; no debe perderse de vista que el sentido general del planteamiento escolástico entiende a los individuos fundamentalmente como comunidad de seres con un destino común. En otras palabras: el bien personal de un hombre redunda en el bien del cuerpo social. Ello, porque el concepto clásico de sociedad civil es una analogía del concepto teológico de "cuerpo místico", en el cual la perfección de la parte apunta directamente la perfección del todo; no en una perspectiva cuantitativa o material, sino en términos cualitativos y espirituales. Así pues, el cumplimiento de la ley que apunta al propio bien del sujeto, sin ser una exigencia eficiente en términos de exterioridad fáctica, no se encuentra en este planteamiento al margen del bien común de la sociedad; $y$, en ese sentido, no constituye un ámbito separado de ésta. La consideración contraria guarda en su núcleo una prioridad consciente o inconsciente del poder (o capacidad de la norma de ser coactiva) sobre la idea de bien común; mucho más amplia y trascendente.

cho, algo que depende simplemente del acuerdo. Cf. Lira, $\mathrm{O}, \mathrm{H}$ orden político, Editorial Covadonga, Santiago, 1985, p. 39 ss

95 La ley injusta no constituye ley; y puede llegar a darse la posibilidad del derecho a rebelión por parte de los destinatarios de esa norma que violenta derechos cuyo carácter más específico es estar atribuidos por contenidos que escapan a la voluntad del legislador humano.

96 Sum. Teol., II-II, q.57, a.2

97 Sum. Teol., I-II, q.95, a.2. Cf. también la interesante exposición de García-Huidobro, J., Razón práctica y Derecho Natural, EDEVAL, Valparaíso, 1993, p. 171 ss

98 Thomasius.

99 Cf. Hervada, J., Historia de la ciencia del Derecho Natural, EUNSA, Pamplona, 1991, p. 285 
Resulta, por lo tanto, que en esta tesis tanto el derecho de cada individuo, como el debitum de la ley se explican por una referencia a algo trascendente a la simple voluntad constitutiva del legislador; y por lo tanto, la ley positiva -expresión de ese poder legislativo- no se encuentra carente de contenido, sino que posee una materia tan específica y delimitada que incluso puede autorizar, en ciertas circunstancias, el legítimo derecho de rebelión por parte de los subordinados, cuando dicho contenido no sea respetado por un determinado gobernante. En este planteamiento, la respuesta a la heteronomía de la ley es muy clara: desde el momento en que se reconoce que hay cosas en el mundo sensible que no dependen en su existencia del sujeto que las conoce, la deducción de la causa eficiente y del orden consecuente que de ella fluye no ofrece mayores dificultades. Para disentir, es preciso ubicarse en los cimientos mismos del edificio conceptual, de otra manera, la crítica es globalmente irrelevante o muy particular ( $y$, por lo tanto, acepta implícitamente todo el resto de la argumentación).

Esta crítica en los inicios es lo que llevará a Kant, como sabemos, a plantear una tesis fundada en la autonomía de. la voluntad y de la ley, concebida como algo absolutamente autónomo.

\section{9- Voluntad autónoma y posibilidad de obrar}

El principio más universal y fúndante de la filosofía kantiana sobre el derecho -así como los principales contenidos en torno al tema- se encuentra formulado en la Metafísica de las Costumbres; y se expresa en la siguiente proposición imperativa:

Obra exteriormente de tal manera que el libre uso de tu albedrío pueda estar conforme con la libertad de todos según una ley univerșal ${ }^{100}$.

La filiación intelectual de este principio es bastante lógica, si tenemos en cuenta todo lo que hemos dicho hasta ahora sobre la tesis kantiana. Vamos, sin embargo, a referirnos brevemente al sentido de este axioma, con el objeto de precisar, más en concreto, la noción de trascendencia jurídica, tal y como se deduce del planteamiento crítico. Hay que tener en cuenta que ya en el prefacio del libro que tratamos (el cual reúne dos textos de Kant: Principios metafísicos del Derecho y Principios metafísicos de la moral) explica el regiomontano que su obra debe entenderse en armonía con el contenido de la KrV. Como dice Rodríguez Luño, "los elementos que componen la Metafísica de las costumbres no suponen una novedad respecto de sus obras anteriores. Se trata más bien de una respuesta de conjunto a las instancias y problemas que inspiraron sus primeros pasos en el terreno de la filosofía moral" ${ }^{101}$. Es decir, son la conclusión en el terreno moral jurídico de los axiomas trazados en las críticas anteriores.

Ahora bien, si la ética se planteaba en $K p V$ en términos de la bondad o maldad de las acciones del sujeto ( $y$ cuyo valor no pasaba de ser simplemente formal; a partir de su carácter de norma aplicable a todos los casos y situaciones), el derecho en cambio se perfila aquí como legalidad, constituyendo un conjunto de reglas y normas que configu-

100 Metafísica de las Costumbres; principios Metafísicos del Derecho, Introducción, pág. 231.

101 Rodríguez Luño, A., Immanuel Kant: Fundamentación de la Metafísica de las Costumbres. Magisterio Español, col. Crítica Filosófica, Madrid, 1977, pág. 21 
ran externamente dicha característica en los actos humanos, pero sin abandonar la fundamentación puramente formal de toda nórma que se encuentre fuera del mundo simplemente natural y necesario (mussen). Efectivamente: después de haber diseñado el comportamiento moral del sujeto espiritual, fundado solamente en la autonomía de la voluntad (sollen); queda por resolver la manera en que dichas libertades se articulan, de modo que puiedan constituir, en su conjunto, una sociedad en la que los hombres que la conforman puedan desarrollar su espacio vital sin interferencias por parte de las autonomías individuales ajenas.

Este es el marco de la teoría jurídica kantiana, formulado ya en el imperativo anterior: combinar, por una parte, la autonomía normativa de la voluntad individual, con un determinado espacio en el que confluyen multitud de voluntades, de tal manera que esas libertades absolutas no se estorben unas a otras. Esto presenta una aporía importante: si se asegura por un lado que la voluntad constituye formalmente normas universales y válidas; no puede por el otro afirmarse que la validez de ese imperativo moral o legal depende de que no interfiera los imperativos ajenos, puesto que, o resulta que la afirmación es falsa, o que la voluntad no es, de hecho, completamente autónoma. Kant no logra obtener una coherencia suficiente en esto, y, como afirma Carpintero, le lleva a proposiciones que, desarrolladas en sus últimas consecuencias, se hacen mutuamente insalvables ${ }^{102}$. Esto conduce a un universo en que el derecho, la libertad externa o jurídica, se reduce a la simple posibilidad de obrar.

Sabemos que el regiomontano divide el derecho en natural y adquirido. El primero es la propia libertad del sujeto, entendida como independencia de coacción arbitraria y externa; y que puede sobrevivir conjuntamente con la libertad de todo otro individuo, según una ley universal ${ }^{103}$. El derecho adquirido, por el contrario, se funda en la voluntad del legislador, y puede ser privado o público ${ }^{104}$. El problema se presenta, justamente, ante la exigencia de derecho público por la cual el sujeto debe "salir de su estado de naturaleza" para entrar con los demás hombres "bajo relaciones de coexistencia necesaria" en un determinado Estado de Derecho ${ }^{105}$.

La existencia necesaria de la sociedad civil ${ }^{106}$, hace también necesaria la existencia del Derecho. Esto significa que se debe tomar como punto de partida el arbitrio o autonomía individual y regularlo de una forma conveniente y consecuente; pero sin indicar ningún comportamiento concreto. Por ello, el principio superior del derecho viene a

102 Cf. Carpintero, F., la Cabeza de Jano, Servicio de Publicaciones de la Universidad de Cádiz, Cádiz, 1989. Introducción, pág. 14 ss

103 Metafísica de las.... I, B, pág. 237

104 El derecho privado tiene por Objeto normar las relaciones entre los individuos considerados en tanto individuos, y su espacio o contenido propio es la propiedad, y los actos jurídicos que de ella emanan. El derecho público, por el contrario, se dedica a reglar las relaciones y acciones de los individuos en la medida en que forman parte de un Estado.

105 Metafísica de las..., I/1,cap.42, p.307

106 Para demostrar este aserto Kant se apoya en la tesis contractualista de Russeau, por la cual los hombres ren uncian a su libertad externa, para recuperarla de inmediato una vez integrados en la sociedad, que es el mismo pueblo considerado como un Estado. 
ser la simple expresión de la "forma del derecho". Esto es la transposición del formalis'mo ético, que hemos descrito antes, al ámbito jurídico ${ }^{107}$.

La solución kantiana deja abierto el problema de la absolutez o relatividad de la trascendencia jurídica. Si se tiene en cuenta el sistema especulativo propuesto en las respectivas Críticas, debemos inclinarnos por la total inmanencia y autonomía de la ley y sus contenidos respecto de la voluntad individual. Sin embargo, la afirmación de que esas libertades deben respetarse mutuamente en el seno de una comunidad, de modo que todos los miembros tengan el derecho y la capacidad de obrar según su voluntad autónoma y libre, se plantean problemas de índole teórica y práctica que no se resuelven a simple vista con los propios elementos sistemáticos que otorga la tesis. En la perspectiva teórica, la consideración del respeto eterno a las voluntades ajenas relativiza ipso facto la inmanencia volitiva proclamada en la seguridad especulativa y estructural de $K p V$. Ahora bien, desde el punto de vista concreto, el problema se hace mucho más acuciante, pues Kant no ofrece posiciones particulares que hagan el resultado de la premișa algo menos forzado. En el orden de los hechos, ¿cuál es la forma propuesta en que algo que se predica absoluto se relativice a otros "absolutos" y siga poseyendo simultáneamente la calidad de tal?.

Como acabamos de ver, las dos nociones de trascendencia en juego tienen resultados muy diferentes en lo que a conclusiones jurídicas se refiere. Sin ánimo de formular una crítica de estos planteamientos, parece que, en principio, la tesis de la trascendencia kantiana resulta inviable a la hora de explicitar y coordinar las consecuencias jurídicas.que de ella se deducen (ello sin hacer referencia a la cuestión de la verdad o falsedad de sus formulaciones de fondo). Una vez más, comprobamos la intrínseca dependencia que tienen las argumentaciones prácticas en relación con las posiciones teóricas, y lo poco prudente que resulta prescindir de dicha vinculación. Creemos, como principio de análisis de las cuestiones propuestas, que la clave más cierta para distinguir la veracidad de un determinado sistema filosófico es su adecuación con la realidad que intenta explicar, y que ello pasa-como enfoque metodológico- por extraer todas las conclusiones prácticas de un determinado planteamiento, y analizar acto seguido su íntima coherencia y posibilidad, a la luz del comportamiento real del hombre y de los grupos humanos. 